\title{
EFEITOS DE EGRÉGORA DOS GRUPOS CONSTELARES, COM MENTORIA DO PROFESSOR PAULO CASSIANO
}

\author{
Jussiguelli Marcondes Maranho ${ }^{1}$ \\ Paulo Cesar Félix Cassiano ${ }^{2}$
}

RESUMO: O estudo dos benefícios relacionados ao efeito fenomenológico em uma egrégora, cujo objetivo é aplicar ensinamentos de autoconhecimento, práticas de constelação familiar, programação neurolinguística e hipnose, ainda é escasso na literatura. Com o objetivo de avaliar o efeito fenomenológico em uma egrégora formada por grupos de alunos do Constelares, curso ministrado pelo professor, terapeuta e constelador Paulo Cassiano, entre Julho de 2020 e Novembro de 2020, foi realizada uma pesquisa exploratória descritiva, a partir de um questionário aplicado aos 69 alunos. Foi elaborado um termo de consentimento e uma pesquisa de levantamento literário. Gráficos foram elaborados com as mensurações das respostas do formulário https://forms.gle/X4LEMoTTfWSQYV9t9. Os resultados preconizaram os benefícios das práticas aplicadas, dentro da egrégora, que comprovaram uma melhoria de $86 \%$ na visão de vida dos participantes.

Palavras-chave: Autoconhecimento. Egrégora. Grupos costelares.

\footnotetext{
Professora, palestrante, pesquisadora, Mestre em Agronomia (UFU), Engenheira Agrônoma, Bióloga, Química (UFU) e, Especialista em Gestão Pública (UFU) e Gestão Ambiental (Católica). Graduanda de Psicologia na Universidade Federal de Uberlândia (UFU). Possui II anos de experiência em multinacional, com atuação em vários projetos de melhoria de processos e área de qualidade. Desde 2015 é professora do ensino superior nos cursos de Agronomia, Agronegócio e outras, atuando como pesquisadora em projetos científicos. Coach certificada pelo IBC - Instituto Brasileiro de Coaching Professional \& Self Coaching, Psicanalista, Thetahealer, Master Reiki, benzedeira, especialista em diversas técnicas holísticas para terapias integralistas. E-mail: jussiguelli@gmail.com.

2 Professor de autoconhecimento, palestrante, pós graduado em neurociências e física quântica, constelador familiar, hipnoterapeuta clínico, terapeuta de técnicas de expansão da consciência, foi facilitador do curso de Barras Access técnica americana presente em i7o países com 25 anos de existência, Coach de presença, instrutor de consciência, mentor de projetos, Consultor, administrador com MBA em Marketing estratégico, é professor universitário, lidera um movimento de estudos de autoconhecimento para expansão da consciência com presença em 20 países e 380 grupos no Whatsapp, sendo a maior comunidade desta área na América latina trabalhou em mais de roo projetos sociais com lideranças, Startups, lidera movimento nacional quânticos, foi Mentor de diversos Projetos, têm formação Internacional em Coaching Integral Sistêmico pela FEBRACIS - Federação Brasileira de Coaching Integral Sistêmico certificado Florida Christian University (FCU), Coach certificado pelo IBC - Instituto Brasileiro de Coaching - Professional \& Self Coaching - Certificações internacionais BCI - Behavioral Coaching Institute, ICC - International Coaching Council, ECA - European Coaching Association, Global Coaching Community, International Association of Coaching Institutes, Metaforum International - Coaching. 2.0 pela $\mathrm{R}_{7}$ Coaching, Recebeu título em $201 \mathrm{I}$ de Embaixador para a cidadania planetária do World Council of Planetary Citizenship do WCPC/CMCP, organização atuante em todos os continentes do planeta Terra - Flight Of The Eagle (www.wcpc.org.br)
} 
ABSTRACT: The study of the benefits related to the phenomenological effect in an egregore, whose objective is to apply teachings of self-knowledge, family constellation practices, neurolinguistic programming and hypnosis, is still scarce in the literature. With the aim of to evaluate the phenomenological effect in an egregore formed by groups of students from Constelares, a course taught by professor, therapist and constelator Paulo Cassiano, between July 2020 and November 2020, a descriptive exploratory research was carried out, based on a questionnaire applied to the 69 students. A consent form and a literary survey were prepared. Graphs were created with the measurements of the responses in the form https://forms.gle/X4LEMoTTfWSQYV9t9. The results advocated the benefits of the applied practices, within the egregore, which proved an improvement of $86 \%$ in the participants' vision of life.

Keywords: Self-knowledge. Egregore. Rib groups.

\section{INTRODUÇÃO}

Há uma busca constante por equilíbrio e sobrevivência motivada pelos avanços da ciência e da tecnologia, e ao caos. A constelação familiar é uma experiência transitória no processo da evolução espiritual do ser, pois todos necessitam de crescimento interior e de iluminação. Assim, o objetivo é encontrar o rumo da paz, a partir de recomeços e reparações, em processos de sofrimento e/ou redenção (FRANCO, 2008).

A Constelação Familiar, de Bert Hellinger, é uma prática sistêmica empregada em contextos terapêuticos e organizacionais, e é considerada uma técnica baseada nos princípios epistemológicos da ciência moderna. $\mathrm{O}$ inconsciente familiar atua em cada membro de uma família (MARINO; MACEDO, 2018).

Ordens do amor são as leis básicas do relacionamento humano, que são a do pertencimento, da hierarquia, e a do equilíbrio, que atuam ao mesmo tempo, onde houver pessoas convivendo. Segundo Hellinger, as ações realizadas em consonância com essas leis favorecem que a vida flua de modo equilibrado e harmônico, porém, quando transgredidas, ocasionam perda da saúde, da vitalidade, da realização, dos bons relacionamentos, com decorrente fracasso nos objetivos de vida (HELLINGER, 1996).

A constelação familiar é uma abordagem capaz de mostrar com simplicidade, profundidade e praticidade onde está a raiz de um distúrbio de relacionamento, psicológico, psiquiátrico, financeiro e físico, levando o indivíduo a um outro nível de 
consciência em relação ao problema. Portanto, pode ser indicada para todas as idades, classes sociais, e sem qualquer vínculo ou abordagem religiosa (MARINO; MACEDO, 2018).

Os problemas vividos por uma pessoa, segundo a Constelação Familiar, são denominados como "emaranhados", que têm relação com algum tipo de exclusão, injustiça, luto, doença grave, rompimento de vínculos, adoção, suicídio e até brigas por herança. O papel do constelador será identificar o emaranhado e restabelecer no sistema familiar do constelante o fluir das ordens do amor (BERTOCHE, 2013).

A egrégora possui um campo magnético onde se concentra toda energia advinda das relações sociais, onde cada ser humano é único dentro das suas especificidades. Dessa forma, as constelações familiares desvelam o comportamento dos indivíduos, sua forma de ver o mundo através de seus antepassados, refletindo em suas escolhas, sua autonomia, seus medos, entre os demais modos de agir, ver e pensar. A reconciliação se faz necessária para a melhoria do bem-estar dos indivíduos imbricados em conflitos (HELLINGER, 1996).

As constelações identificam os padrões que causam problema, dessa forma, surge a resolução desses padrões conflituosos para colocar em ordem todas as estruturas de memórias do inconsciente, evitando danos e possibilitando a libertação (MARINO; MACEDO, 2018).

Os ciclos repetitivos no contexto das constelações familiares se apresentam dentro das relações sociais de acordo com as vivências passadas de geração em geração, de acordo com as crenças, valores, costumes e princípios de cada família geracional, levando em consideração a estrutura hierárquica que organiza e movimenta o campo de energia oriundo de tais relações. Portanto, a constelação familiar como técnica terapêutica é uma abordagem imprescindível para o desenvolvimento da prática profissional e principalmente para a produção de conhecimentos, ampliando as pesquisas significativas que possibilitem a melhoria das técnicas aplicadas para um melhor aprofundamento e percepção no aprendizado dos discentes em processo de formação profissional (BERTOCHE, 2013). 
HIPÓTESE: benefícios relacionados ao efeito fenomenológico em uma egrégora, cujo objetivo é aplicar ensinamentos de autoconhecimento, práticas de constelação familiar E programação neurolinguística.

OBJETIVO: avaliar o efeito fenomenológico em uma egrégora formada por grupos de alunos do Constelares, curso ministrado pelo professor, terapeuta e constelador Paulo Cassiano, entre Julho de 2020 e Novembro de 2020.

METODOLOGIA: Pesquisa exploratória descritiva, a partir de um questionário aplicado aos 69 alunos do Curso Constelares. Foi elaborado um termo de consentimento e uma pesquisa de levantamento literário. Gráficos foram elaborados com as mensurações das respostas do formulário https://forms.gle/X4LEMoTTfWSQYV9t9.

Resultados esperados: preconizar os benefícios das práticas aplicadas, dentro da egrégora.

\section{JUSTIFICATIVA}

\section{Autoconhecimento e PNL}

Autoconhecimento remete ao ideal de observação do indivíduo a respeito do seu próprio comportamento, sendo que os benefícios e dificuldades são melhor observados quando o indivíduo consegue relatar o que é consciente, dentre seus sentimentos, desejos, pensamentos e ideias (SOUZA e ABREU-RODRIGUES, 2007).

Crenças limitam, mas experiências podem libertar. A negação da realidade pode levar à reatividade por meio da identificação.

Quando temos consequências não esperadas e comportamentos não funcionais à vida, há chances que o novo conhecimento e a percepção e reflexão sobre isto, possibilite abertura de caminhos para a mudança e para o crescimento. Assim, há uma "importância do homem se perceber exato para ser aquilo que é e ser função sadia a si e à sociedade" (VIEIRA, 2017).

O autoconhecimento e o desenvolvimento de habilidades interpessoais são objetos de estudo na área das Ciências Sociais. Muitos resultados evocam tanto sentimentos positivos de possibilidade e segurança, como sentimentos negativos, 
experienciados na forma de incerteza em experiências vivenciais. A aplicabilidade é almejada em prol de qualidade de vida. Quando o homem se autoconhece, ele adquire autorrealização pessoal para a construção de uma sociedade mais humana, utilizando a ciência para esta função (OLIVEIRA et al., 2009).

"Conhece-te a ti mesmo" e "a verdade vos libertará" são afirmativas muito utilizadas em programas de autoconhecimento, quando se solicita a identificação de comportamentos positivos e negativos. Porém, é preciso disciplina e esforço para transformar padrões comportamentais que impedem conquistas pessoais. Autoconsciência e autorresponsabilidade são exigências neste processo. Ao identificar as próprias habilidades e dificuldades, indivíduos conquistam a possibilidade de modificar e gerir emoções e comportamentos, o que os torna amplamente capacitados.

Se você conhece a si mesmo não precisa temer o resultado de ioo batalhas. Se você se conhece, mas não conhece o inimigo, para cada vitória sofrerá também uma derrota. Se você não conhece nem o inimigo, nem a si mesmo, perderá todas as batalhas. (SUN TZU, ARTE DA GUERRA).

Programação NeuroLinguística ou PNL envolve a capacidade de dar o melhor de si mesmo com mais frequência, pois se consagra como método prático e eficaz para realizar uma mudança pessoal. Neuro refere-se ao nosso sistema nervoso, aos caminhos mentais dos nossos cinco sentidos de visão, audição, tato, paladar e olfato. Linguística refere-se à nossa capacidade de usar uma linguagem e a forma como determinadas palavras e frases refletem os mundos mentais, e as linguagens silenciosas que refletem atitudes, gestos e hábitos, revelando os estilos de pensamento, crenças, etc. Programação sugere que pensamentos, sentimentos e ações são simplesmente programas habituais que podem ser mudados pelo upgrade do software mental. Os exercícios envolvem experiências reprogramadoras e transformadoras, e, desta forma, são eficientes.

\section{Sobre a egrégora}

Costa e Santiago (2017, preconizam que uma egrégora é resultante do somatório das energias anímicas de cada um dos membros; é uma poderosa central de energia magnética capaz de interferir e gerar uma série de fenômenos. A egrégora forma-se brotando do altar como tênue fio espiritual para adquirir corpo etéreo com as 
características humanas. Os mais sensitivos percebem esta entidade, ela se mantém silenciosa, mas atua de imediato, dando-lhe assistência espiritual de que necessita, manipulando as permutas, construindo assim a Fraternidade. Ou seja, é uma entidade formada pela força mental e pelas vibrações do conjunto. Egrégora é uma forma de energia criada por pensamentos e sentimentos, que adquire vida e é alimentada pelas mentalizações e energias psíquicas. É uma entidade autônoma que se forma pela persistência e intensidade de correntes emocionais e mentais. Pensamentos e sentimentos fracos criam egrégoras mal definidas e de pouca vida ou duração, porém pensamentos e sentimentos fortes criam egrégoras poderosíssimas e de longa duração.

No apocalipse, João faz os anjos responsáveis pelas nações intervirem, porque somos responsáveis pelos erros coletivos cometidos. Ninguém pode lavar as mãos, como fez Pilatos: guerras, fomes, massacres diminuem nossa liberdade, porque participamos da egrégora da terra; da mesma forma que os genes de nossa hereditariedade marcam a história de nosso corpo. Segunda a Bíblia, cidades inteiras foram punidas por causa da sua egrégora envenenada. Onde dois ou mais se reunirem em meu nome, eu estarei entre eles. $\mathrm{Ou}$ seja: quando duas ou mais pessoas se reúnem ao redor de um único objetivo, estas formas-pensamento se somam e geram algo maior, mais dinâmico. E quanto mais concentrados, intensos e constantes forem estes pensamentos, maior o campo de atuação desta egrégora.

É um princípio de vida e um misterioso centro energético que se manisfesta através da intuição e está à disposição. A egrégora é sentida, é energia pura e consolidase quando não há sentimento material, formando a cadeia de união, promovida pela

espiritualidade. É nesse momento onde todos os sintonizados no mesmo pensamento elevam seus espíritos ao divino e então, se faz realizar o objetivo maior dessa cadeia, formando assim, uma egrégora muito forte e que é sentida por todos, desde que estejam irmanados dos mesmos pensamentos.

\section{Sobre a metodologia e ferramentas de mensuração}

As ciências sociais tratam de eventos do ser humano que denotam subjetividade e imprevisibilidade. Os fenômenos humanos não ocorrem de acordo com uma ordem semelhante, lidam com entidades que não são passíveis de quantificação, o que torna 
difícil a comunicação dos resultados obtidos em suas investigações, e pesquisadores sociais, por serem humanos, trazem para as suas investigações certas normas implícitas acerca do bem e do mal e do certo e do errado, prejudicando os resultados de suas pesquisas. A ciência se vale fundamentalmente de método experimental, que exige, entre outras coisas, o controle das variáveis que poderão interferir no fenômeno estudado. Os fenômenos sociais, por outro lado, envolvem uma variedade tão grande de fatores, que tornam inviável, na maioria dos casos, a realização de uma pesquisa rigidamente experimental. Gil (2009).

A ciência tem como objetivo fundamental chegar à verdade dos fatos. Neste sentido, não se distingue de outras formas de conhecimento. O objetivo fundamental da pesquisa é descobrir respostas para problemas mediante o emprego de procedimentos científicos.

As pesquisas exploratórias servem para conhecimento de temas e fatos menos estudados e menos conhecidos, sendo uma etapa inicial para um posterior aprofundamento temático. Pesquisas descritivas servem para encontrar e descrever características de certa população, com a utilização de técnicas padronizadas de coletas de dados. As pesquisas explicativas seriam as mais complexas, e tentariam encontrar fatores que favorecem a ocorrência de fenômenos e se valeriam basilarmente do método experimental. A execução da pesquisa pode ser realizada por coleta documental, observação, entrevista, questionário, formulário, medidas de opiniões e atitudes, técnicas mercadológicas, testes, sociometria, análise de conteúdo e história de vida.

O autor preconiza que o questionário deve ser aplicado somente após a formulação do problema e da revisão de literatura. Determinar os objetivos e construir hipóteses, o delineamento da pesquisa, a amostra, conceitos e variáveis, são características a serem planejadas antes da elaboração do instrumento de coleta de dados, para que as respostas possam ser analisadas e interpretadas. Assim, o questionário torna-se uma técnica de investigação com questões que possuem o propósito de obter informações, sendo muito importante na pesquisa científica, especialmente nas Ciências Sociais. 
Assim, o questionário é uma técnica viável e pertinente em pesquisas de cunho empírico, que envolvem opinião, percepção, posicionamento e preferências dos pesquisados. Neste sentido, busca-se destacar a forma pela qual são construídas as perguntas do questionário, atentando-se para o conteúdo, número e ordem das questões, uma vez que as perguntas são as responsáveis pelo alcance das respostas ao desenvolvimento dos trabalhos.

Melo e Bianchi (2015), afirmam que o questionário de pesquisa é uma das ferramentas mais utilizadas por pesquisadores em Ciências Sociais, e a etapa de elaboração de perguntas é essencial para que cumpra seu papel na coleta de dados de maneira a revelar, da melhor forma possível, a realidade dos fatos ocorridos dentro do alvo do estudo proposto.

\section{Sobre a metodologia (pesquisas realizadas na área de terapias energéticas)}

$\mathrm{Na}$ pesquisa de Gontijo e Nunes (2017), II8 profissionais da saúde (médicos, fisioterapeutas, cirurgiões-dentistas, enfermeiros, farmacêuticos, biomédicos, nutricionistas, psicólogos, terapeutas ocupacionais, fonoaudiólogos e assistentes sociais, com atuação no SUS dos municípios de Itumbiara e Panamá (Goiás) e Araporã (Minas Gerais) do Sistema Único de Saúde, em 2014 analisaram dois grupos quanto ao conhecimento e crenças. Com a análise de cluster (questionário em grupos), concluíram que havia pouco conhecimento sobre a Política Nacional de Práticas Integrativas e Complementares e falta de credibilidade nas práticas integrativas e complementares, que englobam, conforme a lei institucionalizada pelo SUS, práticas da medicina tradicional chinesa (acupuntura, homeopatia, fitoterapia, termalismo/crenoterapia (águas termais ou acrescidas de nutrientes) e antroposofia), as quais englobam o equilíbrio do $\mathrm{Ki}$ ou energia vital, melhorando a circulação energética nos meridianos existentes no corpo. O questionário continha 12 perguntas no formato de questões abertas e fechadas, que abordavam as características profissiográficas dos participantes (idade, sexo e categoria profissional), bem como temas relativos aos conhecimentos em relação às PICs e à PNPIC e à credibilidade em relação às PICs. Foi elaborado um termo de consentimento livre e esclarecido antes da aplicação do questionário. Foi aplicada a análise descritiva dos dados, assim como a de 
cluster (two--step cluster), técnica de análise exploratória pela qual se podem agrupar os dados de modo que os registros dentro de um grupo sejam similares.

Martins (2016), em seu trabalho, utilizou escalas sobre a qualidade de vida e dor, sendo elas de Whocol-bref que avalia domínios físicos, psicológicos, relações sociais, meio ambiente; SF-36 que avalia capacidade funcional, limitação por aspectos físicos, dor, estados geral de saúde, vitalidade, aspectos sociais, limitação por aspectos emocionais e saúde mental; EVA (escala analógica visual) na avaliação da dor; e relatos em prontuário médico referindo condições clinicas antes, durante e após a intervenção nutricional e homeopática.

Del Pilar, Dacal e Silva (2018), realizaram um estudo observacional retrospectivo, de corte transversal, que utilizou registros em prontuários médicos. Observaram-se, a partir da análise dos dados, impactos aparentes das terapias complementares no alívio de sintomas psicológicos, emocionais e físicos, tais como ansiedade, estresse e dores no corpo, entre 2016 e 2017. O atendimento é exclusivamente voltado para pacientes matriculados na unidade e funciona semanalmente, apenas em um turno da semana. Até o momento, as práticas oferecidas no centro especializado são reflexologia podal e reiki. Deve-se ressaltar que a escolha por ofertar tais práticas relaciona-se à qualificação dos profissionais envolvidos com a implantação do ambulatório. A metodologia empregada neste estudo foi quantitativa, aplicada por meio de questionário estruturado, tido como protocolo de atendimento pela equipe responsável após um ano de funcionamento do ambulatório e anexado ao prontuário dos usuários. Nesse questionário, apresentam-se dados sobre o perfil dos pacientes (idade, tempo na unidade, patologia de base, forma de encaminhamento para o ambulatório); queixas iniciais; modalidades de atendimento em Pics a que se submeteu; frequência no ambulatório; e percepção de melhora dos sintomas numa escala de intensidade de o a 100\%. Os dados foram tabulados, tratados estatisticamente e apresentados por meio de porcentagem simples, utilizando o programa Microsoft Excel ${ }^{\circledR}$ 20Io. Deve-se ressaltar que o estudo observou e cumpriu os princípios éticos para a publicação de artigos com resultados envolvendo seres humanos segundo a 
declaração de Helsinki, sendo aprovado pelo Comitê de Ética em Pesquisa (CEP) da Secretaria da Saúde do Estado da Bahia (Sesab), CAAE no 71345317.7.00oo.0052.

Demir, Can e Kelam (2015), realizaram um estudo na Ásia com pacientes que apresentavam câncer e sintomas de fadiga, estresse, ansiedade e dor. Determinaram o efeito do Reiki enviado a distância por cinco noites, durante 30 minutos. Foi realizada uma entrevista presencial e características pessoais e relacionadas ao paciente foram avaliados usando o formulário Características do Paciente. O Comitê de Pesquisa da Universidade de Istambul (Instituto de Oncologia) aprovou este estudo. Os pacientes foram informados e o consentimento verbal foi obtido. A estatística descritiva, média, mediana, freqüências e porcentagem foram utilizados para mostrar sociodemográficas e doenças ou tratamentos relacionados às características dos pacientes. Havia um grupo controle, que foi predominantemente masculino (72,7\%), indivíduos casados (60\%) e diplomados do ensino fundamental (60\%). Um formulário de características pessoais, com anamnese de dor, estresse e fadiga foi avaliado de acordo com uma escala de classificação numérica, o qual possuía questões pessoais (idade, nível de renda, status de emprego e outros), e características relacionadas à doença (diagnóstico, cirurgia terapia, radioterapia).

Oliveira (2013) realizou um trabalho com o objetivo de avaliar se a terapêutica Reiki poderia produzir alterações psicofisiológicas e de qualidade de vida em idosos com sintomas de estresse este estudo, que durou oito semanas, mensurou em um grupo de voluntários que receberam Reiki e um grupo que recebeu um tratamento Placebo, respostas psicológicas como níveis de estresse, ansiedade, depressão, percepções de tensão e bem estar, qualidade de vida, além de respostas fisiológicas como temperatura periférica, tensão muscular e condutância elétrica da pele. O conjunto dos resultados obtidos sugere que a terapêutica Reiki produz alterações psicofisiológicas e de qualidade de vida em idosos compatíveis com uma redução significativa de estresse. Após a assinatura do Termo de Consentimento Livre e Esclarecido (TCLE), preenchimento de questionário de identificação pessoal e exame clínico com uso de anamnese, aplicadas e interpretadas por um médico da equipe de pesquisa, foi efetuada a aplicação do Inventário de Sintomas de Estresse para Adultos de Lipp (ISSL), sendo 
50 indivíduos selecionados, de acordo com os critérios de inclusão que estabeleciam que os voluntários, de ambos os sexos, deveriam ter entre 60 a 75 anos e apresentar escores indicativos de, no mínimo, fase de resistência ao estresse, mensurados através do ISSL.

Antes do início do estudo os participantes foram alocados em grupos, de forma randomizada, através do software Microsoft Excell ${ }^{\circledR}$ : I) Grupo Placebo, que em oito sessões realizadas semanalmente, em dias diferentes, receberam uma intervenção que simulou aplicações Reiki, administradas por pessoas que não tinham formação ou qualquer experiência com a técnica. II) Grupo Reiki, que receberam em oito sessões realizadas semanalmente, em dias diferentes, aplicações da técnica Reiki, estilo Usui Tradicional, por terapeutas com mais de cinco anos de prática na técnica e graduação de Mestre Reiki. Durante um total de 25 minutos por dia de participação, os voluntários permaneceram deitados sobre uma maca em decúbito dorsal, com os olhos fechados, em ambiente silencioso com luminosidade e temperatura controladas. A intervenção aplicada, tanto pelas pessoas que simularam a administração do Reiki, quanto dos terapeutas Reiki, consistiu na imposição de suas duas mãos a cada três minutos, sobre as regiões corporais cranial parietal, cranial frontal, cranial temporal, torácica e umbilical.

Para a análise de dados, os níveis de estresse mensurados pelo ISSL foram analisados utilizando-se do teste não paramétrico de Kendall. Nos inventários BAI, BDI, EAPBE, EAPTM, WHOQOL-roo e WHOQOLOLD foi realizada uma Análise de Variância de 2 vias (ANOVA) para medidas repetidas considerando-se o grupo como variável independente e as medidas de cada instrumento como variável dependente.

Os dados coletados, utilizando-se o fisiógrafo foram analisados empregando-se Análise de Variância de 2 vias (ANOVA) para medidas repetidas considerando-se como variável independente o fator grupo e como dependente as medidas de TE, EMF e CEP nos momentos Antes da intervenção, Durante a intervenção e imediatamente Depois da intervenção na mesma semana. Da mesma forma foram realizadas comparações entre as semanas I, 4 e 8 para o fator grupo. Em todos os dados analisados 
por meio da Anova, realizou-se um teste de normalidade (Teste de Kolgomorov) e homogeneidade (Teste de Levene). Além disso, a análise da Anova foi corrigida pelo teste de esfericidade de Mauchly. Quando necessários também foi realizado z-score no tratamento dos dados. Quando detectadas diferenças significantes pela ANOVA realizou-se um teste a posteriori de Newman Keuls com objetivo de detectar as diferenças entre grupos e interações tempo X grupo.

\section{Sobre as constelações sistêmicas e as publicações na área do direito}

Petruzella e Socorro (2009) analisaram a utilização da constelação familiar sistêmica como alternativa para a resolução de processos judiciais, com ênfase nos que tramitam nas Varas de Família, a partir do estudo da teoria de Bert Hellinger. Adotouse o método indutivo, o qual possibilitou o estudo a partir de uma análise específica para se chegar a uma conclusão generalizada, como também a abordagem qualitativa, indicando uma pesquisa exploratória descritiva, uma vez que se tratou de uma investigação sobre um tema pouco debatido com a descrição detalhada da dinâmica sistêmica. Houve êxito da aplicação da constelação como mecanismo para se chegar à autocomposição, tendo em vista que ela humanizou as relações judiciais e diminuiu a intervenção do Poder Judiciário na esfera pessoal das partes.

Segundo as autoras:

“Com o auxílio da abordagem fenomenológica, Hellinger descobriu que a consciência é heterogênea, ou seja, formada por camadas, que acarretam uma variação do comportamento humano segundo o grupo em que está inserido. Ao partir desta premissa, concluiu acerca da existência de uma consciência de vinculação, que origina uma repetição de comportamentos entre membros de um mesmo sistema familiar. Já em relação aos campos morfogenéticos, estes consistem em energias virtuais, nas quais as informações são transmitidas em determinado espaço e tempo, auxiliando para a formação de memórias familiares e provocando o surgimento da ressonância mórfica, em que o passado interfere no presente. Os campos morfogenéticos de qualquer organismo vivo particular, digamos, de um girassol, são moldados pelas influências das gerações precedentes de girassóis. A ressonância mórfica não permite, contudo, explicar como é que aparecem os primeiros campos deste tipo. Dentro do âmbito da 
evolução biológica, os campos de girassóis estão ligados, de maneira estreita, aos campos de outras espécies aparentadas, tais como as alcachofras de Jerusalém descendem, sem dúvida, dos campos de uma longa linhagem de espécies ancestrais. Mas a hipótese da causalidade formativa não permite responder à questão de saber como é que os campos do gênero girassol, ou da família compositae, de que é membro, ou das primeiras células, surgiram. E uma questão de origem, de criatividade. A partir desses estudos, Hellinger denominou essa memória familiar de herança afetiva, já que é responsável pela transmissão de conflitos emocionais ou psíquicos entre membros da mesma família, como, por exemplo, depressão, aborto, suicídio, morte precoce, alcoolismo, entre outros, que repercutem, muitas vezes, em um emaranhamento. Emaranhamento significa que alguém na família retoma e revive inconscientemente o destino de um familiar que viveu antes dele. Se, por exemplo, numa família, uma criança foi entregue para a adoção, mesmo numa geração anterior, então um membro posterior dessa família se comporta como se ele mesmo tivesse sido entregue. Sem conhecer esse emaranhamento não poderá se livrar dele. Em busca da eliminação desse emaranhamento, Hellinger observou o comportamento humano diante do seu seio familiar. Neste momento, fora surpreendido com a atuação de três forças básicas nas relações, as quais, para ele, eram como leis, que, quando desrespeitadas, refletiam negativamente na vida das pessoas.

\section{RESULTADOS}

Após análise dos questionários respondidos no link https://forms.gle/PkZSK99 QgqX ${ }_{5} W_{4} V 8$ por 69 participantes, 59,4\% possuíam de 52 a $7 \mathrm{I}$ anos, e 21,7\% de 42 a $5 \mathrm{I}$ anos; 69,6\% de cor branca; 79,7\% do sexo feminino; 43,5\% moravam com companheiros e 13\% só com os filhos (Figura 24 ). 
Idade

69 respostas

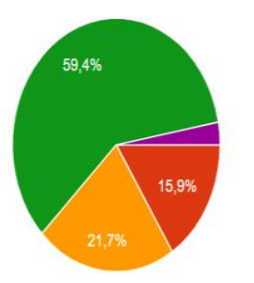

Sexo

69 respostas

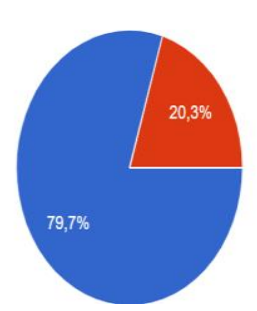

Cor

69 respostas
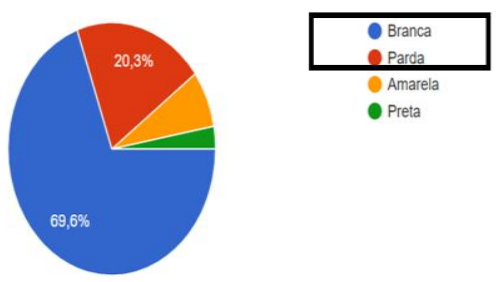

69 respostas
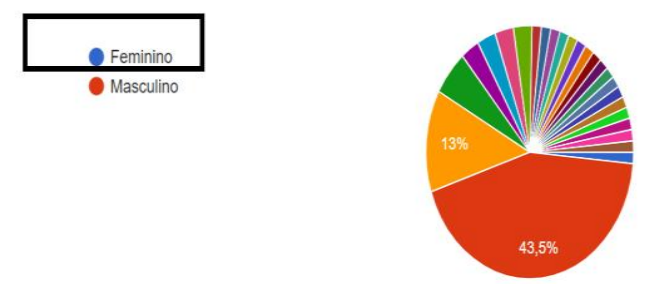

Figura I-Dados pessoais dos participantes.

50,7\% se consideram espiritualista; 31,9\% pós-graduado, e 58\% com ensino superior (completo e incompleto); 30,4\% sem trabalho, e 50,7\% trabalhando (período integral ou parcial); $36,2 \%$, de $\mathrm{R} \$ 3$ a 5 mil reais, e $31,9 \%$, de $\mathrm{R} \$ 6$ a ro mil reais (Figura 25).

Qual sua religião 69 respostas
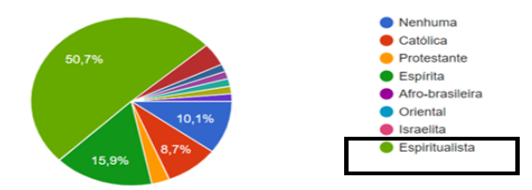

Escolaridade
69 respostas
Está trabalhando no momento

69 respostas
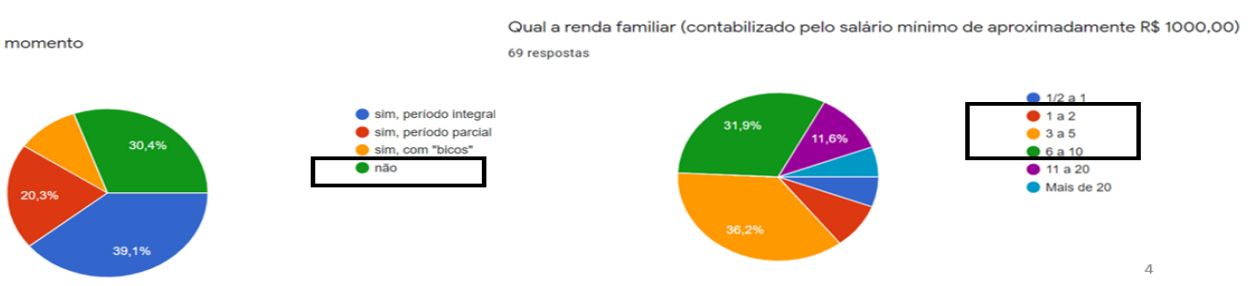
Figura 2-Dados gerais.

A Figura 26 representa o estado de saúde dos participantes, sendo que $42 \%$ se considerava ansiosos, $27,5 \%$ preocupados, 31,9\% inseguros, e 71\%, prósperos e abundantes.
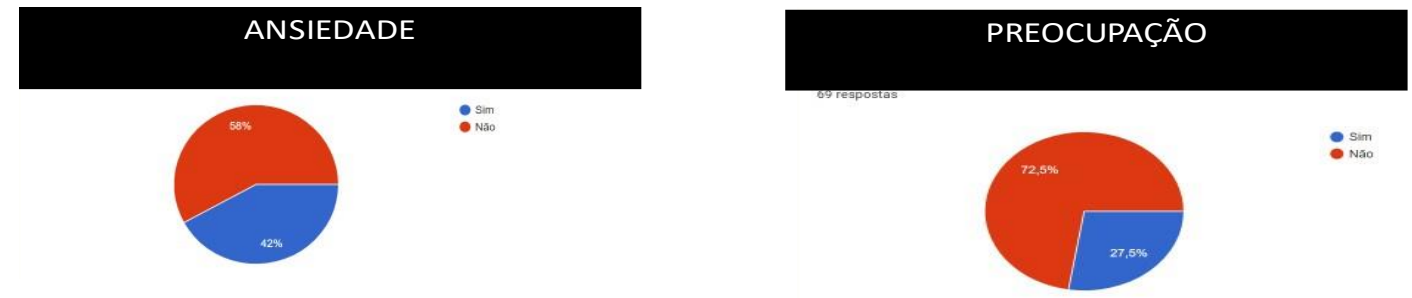

PRÓSPERA E ABUNDANTE?
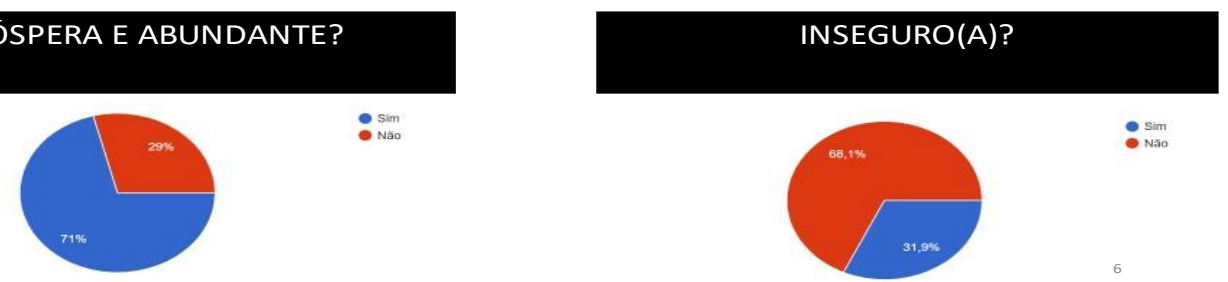

: $\operatorname{sim}$

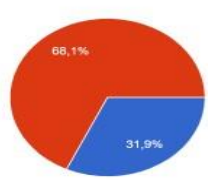

: șim

Figura 3 - Estado de saúde quanto à ansiedade, insegurança, preocupação e visão sobre prosperidade e abundância.

"Você é próspero quando está vivendo em paz, com saúde e em fartura. Embora o pensamento promissor possa significar muitas coisas, ele, basicamente, dará a você força para fazer que os seus sonhos se realizem, seja para que você goze de uma melhor saúde, seja para que tenha um crescente êxito financeiro, uma vida pessoal mais feliz, mais instrução, ou faça mais viagens, ou consiga uma vida espiritual mais intensa" (PONDER, 1962).

Dos que apresentaram estado de saúde que relatava ansiedade, preocupação e insegurança, os principais sintomas observados e reclamados foram de ansiedade, depressão, cansaço mental, insatisfação, mágoa, remorso e arrependimento, e culpa (Figura 27). 
Se apresentar algum destes sentimentos e/ou emoções, marque as opções que indicam os mesmos

70 respostas

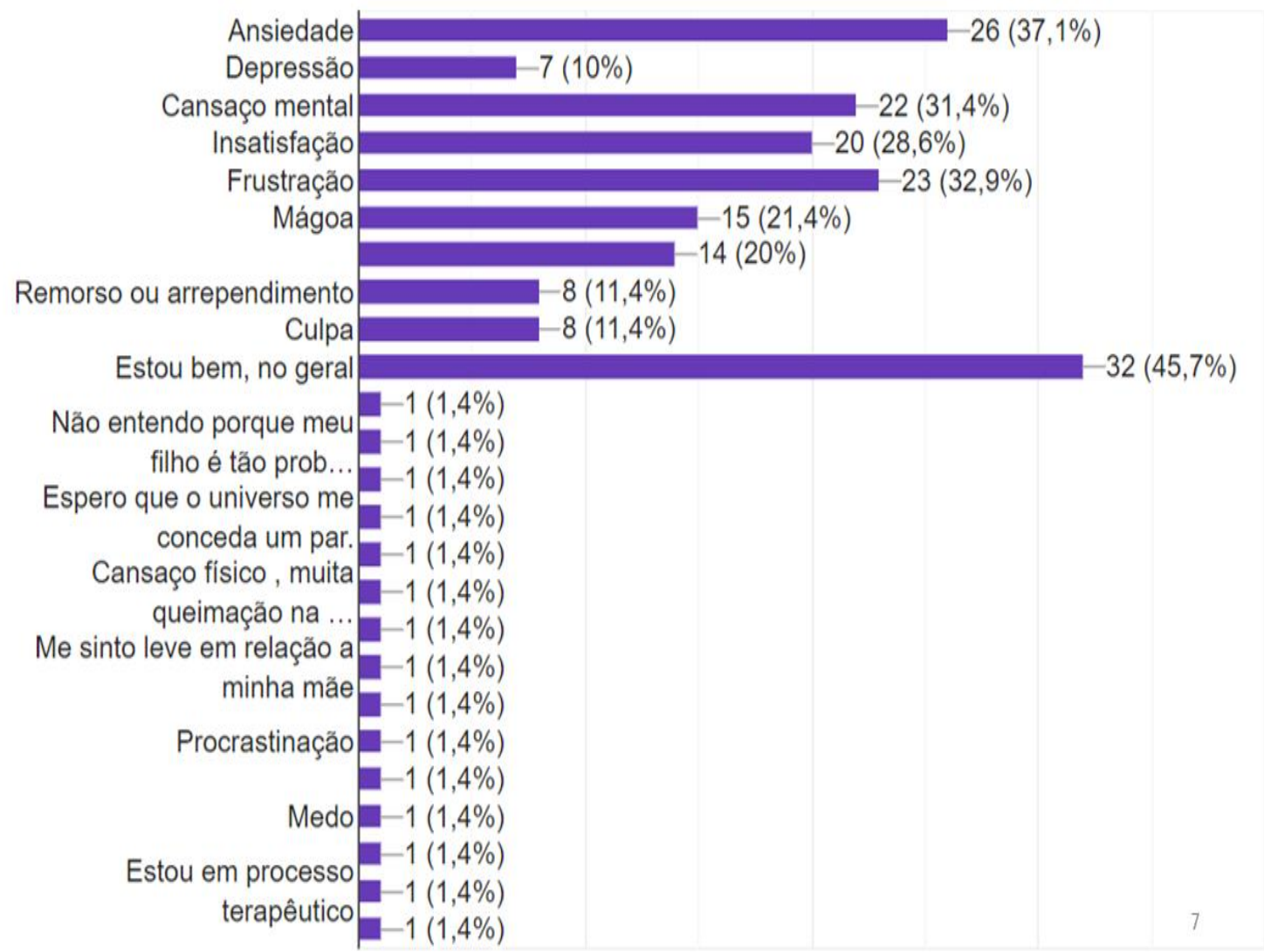

Figura 4 - Estado de saúde - detalhamento dos sintomas .

Sobre a relação com os pais (Figura 28), 44,9\% relatou boa relação, 26,41\% ótima, e ı $8,8 \%$ razoável; o maior desafio era com a mãe para 34,8\%, e para ambos, $26,1 \%$; $45,7 \%$ possuía irmãos; e a maior parte não sabia da existência de irmãos abortados, 42,9\%.

Quando questionados sobre os maiores conflitos existentes com os pais, 59\% os julgava, sem os aceitar como realmente eram, identificando-se aqui arrogância e amor interrompido, o que fere as Ordens do Amor de Hierarquia e Pertencimento, afetando, por consequência, o Equilíbrio na relação. Segundo Bert Helinger, a raiz do problema está no problema do âmbito familiar, quando a ordem não é seguida. Justifica-se, assim, a existência de conflitos nas relações. 


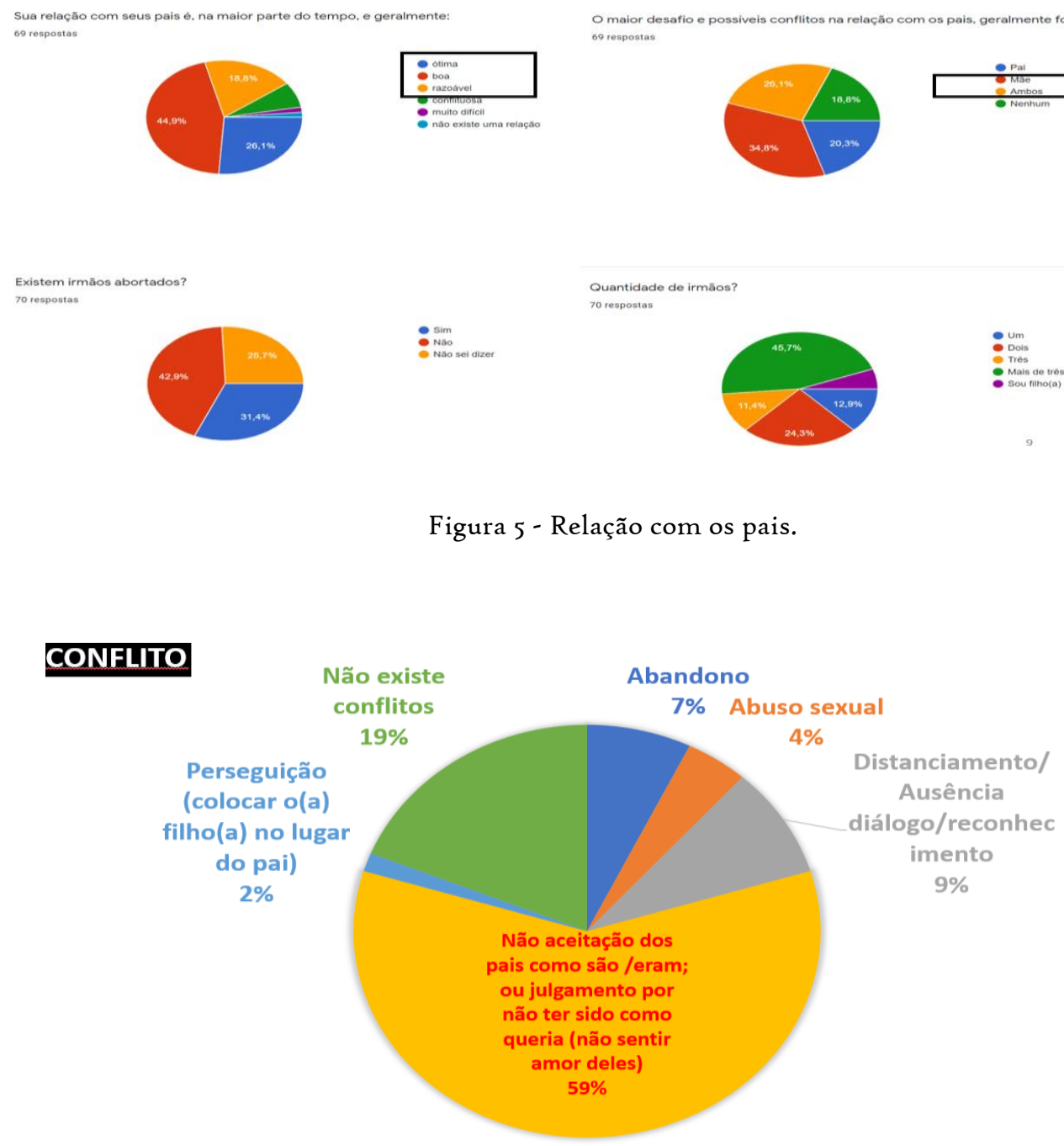

Figura 6 - "Julgamento" em relação aos pais, sobre os principais conflitos.

Após as aulas do professor Paulo Cassiano, as melhorias mensuradas foram da ordem de $86 \%$ na relação com pais. 


\section{MELHORIA: $86 \%$}

Houve melhoria na relação com seus pais após a sua participação na egrégora de autoconhecimento e despertar?

70 respostas

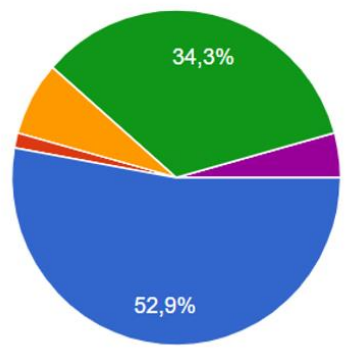

Sim

$$
\text { Não }
$$

Não sei dizer

Meus pais não estão vivos, mas sinto

que sim, dentro de mim

Meus pais não são vivos, então, não

Figura 7 - Melhorias após o Constelares.

Após as aulas do professor Paulo Cassiano, as melhorias mensuradas foram da ordem de $86 \%$ na relação com pais.

Já havia participado de grupos de autoconhecimento antes?

70 respostas

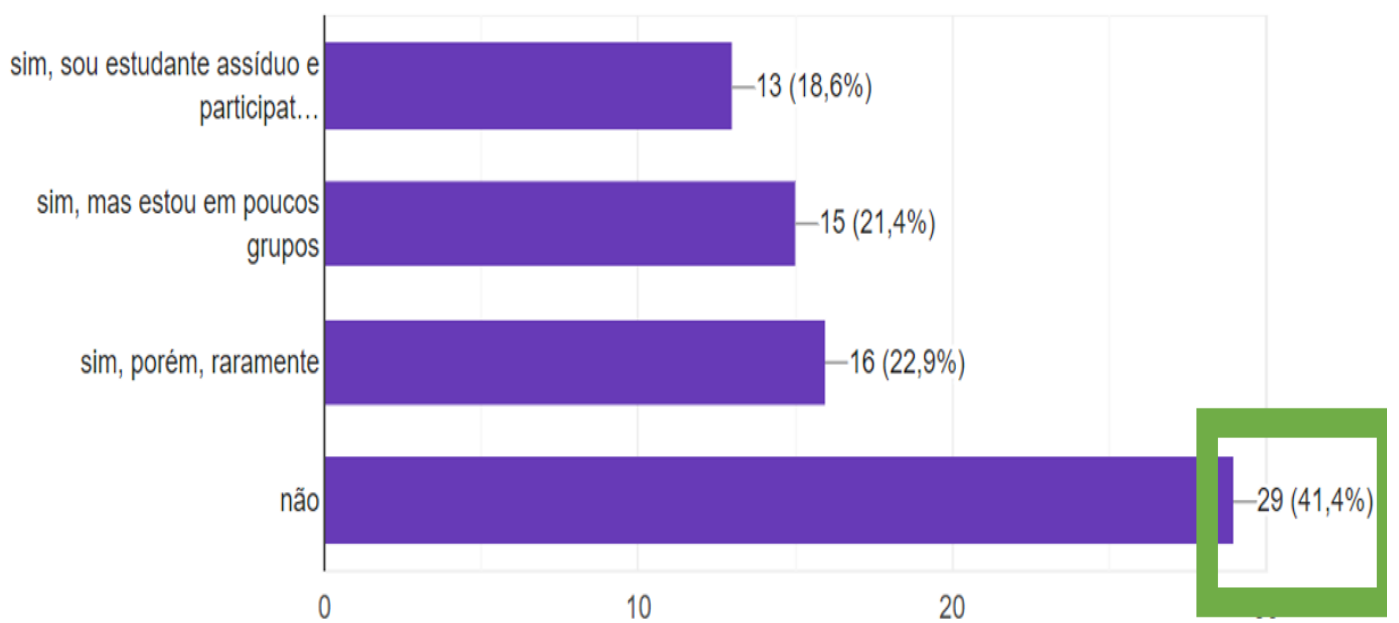

Figura 8 - Noção de autoconhecimento dos participantes. 
Já experimentou beneficios em grupos e/ou egrégoras?

70 respostas

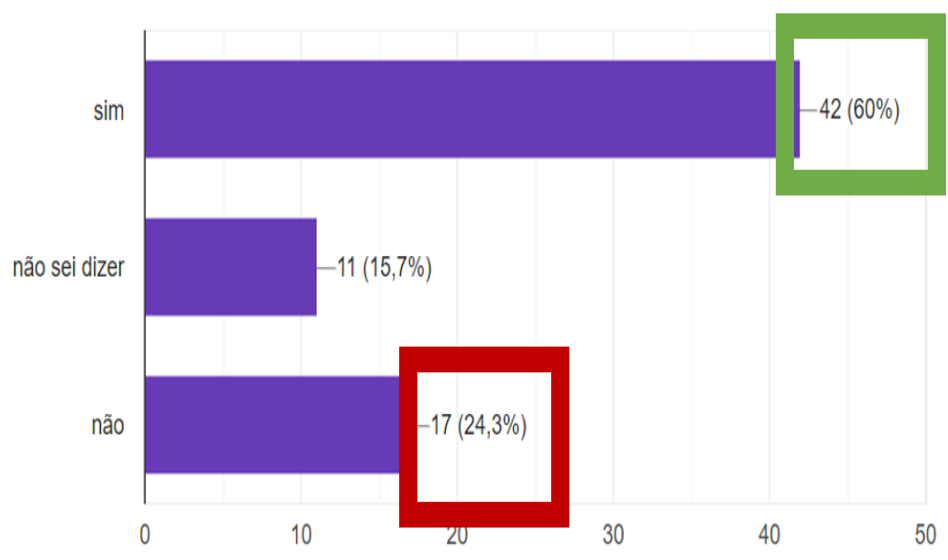

Figura 9 - Participação em egrégoras.

4I,4\% não havia participado de grupos de autoconhecimento (Figura 3I) e, dos que participaram, 60\% já havia experimentado os benefícios de egrégora e/ou grupo (Figura 32).

77\% dos participantes identificaram melhor conexão e cura, com o Constelares, e, I7\%, ressignificação, descoberta e orientação.

\section{MELHORIA: $86 \%$}



Figura 1o - Melhorias após aplicabilidade dos ensinamentos em egrégora. 
Desta forma, concluiu-se que o conhecimento e orientação para o autoconhecimento podem elucidar, promover despertar do nível de consciência e trazer os benefícios de apoio em grupo, auxiliando na reprogramação do subconsciente ao nível coletivo.

Quando um traz sua luz à tona, outras pessoas também são beneficiadas.

\section{REFERÊNCIAS}

ANDREAS, S.; FAULKNER, C. PNL - Programação Neurolinguística: a Nova Tecnologia do Sucesso. Editora Campos, 1995.

BERTOCHE, L. S. Curando Memórias com a Constelação Sistêmica Transgeracional/ Laís de Siqueira Bertoche. In: IV Congresso de Terapia Regressiva, 2013.

CHAER, G.; DINIZ, R. R. P.; RIBEIRO, E. A. A técnica do questionário na pesquisa educacional. Evidência, Araxá, v. 7, n. 7, p. 251-266, 2011.

COSTA, A. M.; SANTIAGO, L. EGRÉGORA MAÇÔNICA: FENÔMENO DA FORÇA ESPIRITUAL. O Buscador - Campina Grande- PB Brasil Ano $2 \mathrm{~N}^{\circ}$ I pag. 32 $-37 \mathrm{jan} / \mathrm{jun}-2017$

Del PILAR, M.; DACAL, O.; SILVA, I. S. Impactos das práticas integrativas e complementares na saúde de pacientes crônicos. RIO DE JANEIRO, V. 42, N. II8, P. 724-735, JUL-SET 2018.

DEMIR, M.; CAN, G.; KELAM, A. Effects of Distant Reiki On Pain, Anxiety and Fatigue in Oncology Patients in Turkey: A Pilot Study. Article in Asian Pacific journal of cancer prevention: APJCP · July 2015 .

FRANCO, D. P.; ÂNGELIS, J. Constelação familiar. Salvador, BA : Livr. Espírita Alvorada, 2008.

GIL, A. C. Métodos e técnicas de pesquisa social. 6- ed. São Paulo: Atlas, 2009.

GONTIJO, M. B. A.; NUNES, M. F. Práticas integrativas e complementares: conhecimento e credibilidade de profissionais do serviço público de saúde. Trab. Educ. Saúde, Rio de Janeiro, v. I5 n. I, p. 30I-320, jan./abr. 2017.

HELlingER, B. Constelações Familiares. Bert Hellinger. São Paulo: Editora Cultrix, 1996. 
MARINO, S.; MACEDO, R. M. S. A constelação familiar é sistêmica? Nova Perspectiva Sistêmica, n. 62, p. 24-33, dezembro 2018.

MARTINS, D. Uma abordagem às Práticas Integrativas e Complementares associadas aos tratamentos especializados em comorbidades crônicas, na Estratégia de Saúde da Família. Trabalho de Conclusão de Curso para especialista em Saúde da Família, a Universidade Aberta do SUS. Universidade do Estado do Rio de Janeiro: Universidade Aberta do SUS. Rio de Janeiro. 2016.

MELO, W. V.; BIANCHI, C. S. Discutindo estratégias para a construção de questionários como ferramenta de pesquisa. R. B. E. C. T., vol 8, núm. 3, mai-ago.2015.

OLIVEIRA, G. F.; DAMASCENO, M. M. S.; BEZERRA, F. W. G.; SILVA, F. S. Trabalhando os conceitos de autoconhecimento e autoconsciência com metodologia vivencial. Revista de Psicologia. Ano 3, No. 7, Fevereiro de 2009 - ISSN ig8I-II79.

OLIVEIRA, R. M. J. Efeitos da prática do Reiki sobre aspectos psicofisiológicos e de qualidade de vida de idosos com sintomas de estresse: estudo placebo e randomizado. São Paulo, 2013. 165p. Tese (Doutorado) - Universidade Federal de São Paulo. Escola Paulista de Medicina. Programa de Pós-Graduação em Psicobiologia.

PETRUZELLA, R. M.; SOCORRO, T. C. A APLICABILIDADE DA CONSTELAÇÃO FAMILIAR SISTÊMICA NA RESOLUÇÃO DOS CONFLITOS NAS VARAS DE FAMÍLIA. Revista Científica da FASETE 2019.I 165

SOUZA, A. S.; ABREU-RODRIGUES, J. Autoconhecimento: contribuições da pesquisa básica. Psicologia em Estudo, Maringá, v. I2, n. I, p. I4I-I50, jan./abr. 2007.

VIEIRA, C. S. Perceber-se e aprender-se: caminho para o autoconhecimento. Saber Humano, ISSN 2446-6298, Edição Especial: Cadernos de Ontopsicologia, p. 42-59, fev., 2017. 